\title{
Global and Entrepreneurial Perspectives for Enhancing Retailing Education: Development of a Hybrid Graduate Course Focused on U.S. and Indian Small Businesses
}

\author{
Ann Marie Fiore \\ Iowa State University \\ Jessica L. Hurst \\ Iowa State University \\ Linda S. Niehm \\ Iowa State University \\ Te-Lin Chung \\ Iowa State University \\ Elena Karpova \\ Iowa State University \\ Amrut Sadachar \\ Auburn University \\ Sanjukta Pookulangara \\ University of North Texas \\ Danielle Sponder Testa \\ Iowa State University
}

This paper provides an approach, based on global and entrepreneurial perspectives, to enhance retailing education. The approach was operationalized through a hybrid graduate course, co-tanght by U.S. and Indian faculty members, which focused on engaging Bloom's higher order cognitive skills in learning about the operation of small retail businesses in U.S. and Indian cultural contexts. The course included interactive learning modules, learning activities, and a student service-learning project. The project required the application of module content in the development of business enhancement plans for small retail businesses and in assessing the plan's applicability to small businesses in an Indian context. 


\section{INTRODUCTION}

A.T. Kearney's report on global retail ("The 2017 Global Retail," 2017) illustrates retail's dynamic nature and its expanding opportunity in countries outside of the U.S., because of the growth of the middle class, acceptance of online shopping, and loosening of governmental regulations, which foster increased consumption and foreign investment. This opportunity calls for U.S. professionals who are not only versed in Western retailing strategies, but who also understand business practices and consumers of other countries.

Higher education has a role to play in preparing future professionals to take advantage of these opportunities. In support, scholars have been proponents of enhancing college student comprehension of (a) the impact of globalization on businesses (Kao \& Mao, 2011) and (b) business operations in a cultural context (e.g., Godiwalla, 2016; Guerin, 2009). Yet, many business schools have not determined how to embed a global perspective in their curricula. Kao and Mao (2011) stated,

The increasing complexity and changing dynamics in the business environment caused by accelerated globalization have made it difficult for business schools to determine how to incorporate these changes in their curricula. Teaching general phenomena in this new global environment is inadequate to prepare business graduates to be globally competitive (p.9).

This difficulty and inadequacy is also true of retailing and merchandising curricula (referred to as retailing herein), which are commonly housed in programs outside business schools. Such curricula receive little scholarly attention in comparison to foundational business school curricula. Moreover, looking at international retailing textbooks (e.g., Alexander \& Doherty, 2009; Sternquist, 2007), the emphasis in the field is on large firms; small firms receive little attention.

Kao and Mao (2011) espoused that curricula should be redesigned to better prepare students to be successful in a global market. The present authors and their collaborators have heeded Kao and Mao's call by formulating an approach, condensed into a course, for better comprehension of retailing industries and businesses in the United States and other global markets. Along with a focus on a global perspective, the approach emphasizes an entrepreneurial perspective, which aligns with, and potentially provides a competitive advantage in, a dynamic market (Zahra, Sapienza, \& Davidsson, 2006; Whalen \& Akaka, 2016), such as global retailing. Morris et al. (2013) indicated that there is a growing need to educate and prepare students through entrepreneurship education for employment in the global marketplace. To fill this and the aforementioned gap regarding a limited focus on small businesses in international retailing, the course also emphasizes entrepreneurship and small businesses.

\section{Focus on the U.S. and Indian Retail Sectors}

Acquired external funding required that curricular development of the project center on U.S. and India retailing. However, as shown next, the retailing industries of the United States and India are integral to the economies of their countries, offer significant opportunity for growth, but are also undergoing dramatic changes and not well understood, which makes targeting them suitable for the course.

The U.S. retail sector is the nation's largest private sector employer, providing one in four U.S. jobs and contributing \$2.6 trillion to annual gross domestic product (GDP) (National Retail Federation, 2015), and employment in this sector is projected to increase 14\% by the year 2020 (National Retail Federation, 2014). Likewise, the retail sector is India's second largest employer; it contributes over $10 \%$ of its GDP and is expected to grow 10\% annually (Dixt \& Singh, 2017; Singhi, Mall, \& Puri, 2016). India's retail sector is in a state of dramatic change (Singh, 2014), and the government has incentivized investment in the domestic retail sector by global investors (Arora, 2017). As the fifth largest retail market globally, India's rate of growth places it as one of the most promising markets for retail expansion (India Brand Equity Foundation, 2017; Dholakia, Dholakia, \& Chattopadhyay, 2012). Relatedly, Western-format (organized) retail is growing in popularity among Indian consumers (Singh, 2014; India Brand Equity Foundation, 2017). Among the foreign retail growth in India, the United States comprises a large share (ANI, 2017; India Brand Equity Foundation, 2017; Joshi, Dheri, Goel, \& Pillai, 2014). Furthermore, the 
growing Indian middle class and resulting consumer market offers opportunities for U.S. entrepreneurs of goods and services (PTI Consultancy, 2017).

However, firms (large and small) often lack the necessary knowledge of foreign consumers, cultures, and business practices to successfully expand to international markets (Wilkinson \& Brouthers, 2006). According to Farrell \& Beinhocker (2017),

Companies that fail to understand the unique desires and tastes of the new Indian consumer will miss out on a half-billion-strong market that along with China ranks as one of the most important growth opportunities of the next two decades (para. 2).

In summary, demand for new Western-format retail stores by Indian consumers and the entry of U.S. brands and retailers to the Indian market calls for U.S. professionals who are not only versed in Western retailing strategies, but who also understand business practices and consumers from the Indian cultural context. Higher education is essential to preparing students to embrace this professional reality.

\section{RE-CONCEPTUALIZING THE PEDAGOGY OF RETAIL EDUCATION}

This section outlines how higher education could incorporate global and entrepreneurial perspectives to better prepare graduate students to assess, develop, and operate small retail businesses in the United States and to assess and take advantage of opportunities globally. Kao and Mao's (2011) goals for business school education - (1) development of knowledge, (2) fostering skills to deal with real word problems, and (3) innovative thinking - should be embedded in any changes to retailing curriculum. Kao and Mao (2011) promoted application of their conceptual framework in the design of a Masters of Business Administration (MBA) program; the present authors believe that these goals also apply to Master's of Science (MS) and Doctor of Philosophy (Ph.D.) programs, as these students perform critical analysis of knowledge and develop creative applications to address real world business problems in retailing in the United States and abroad.

\section{Importance of a Global Perspective}

Kao and Mao's (2011) goals for business-related education included a focus on knowledge and skills needed for careers in the evolving global market. Globalization creates enhanced need for knowledge of goods, services, capital, and information that are exchanged among countries and cultures. The globalization of people also brings a new level of needed skills, interconnectedness, and interdependence in all facets of our lives (Fareed, 2016). This new environment provides unique opportunities for small business owners around the world to directly work with each other (Suominen, 2017). To prepare graduates for the new stage of globalization, intercultural education becomes critical. According to Ferren and Merrill (2013), intercultural education, which the present authors call a global perspective, emphasizes human aspects rather than strictly focusing on business competition and "provides students with the tools to understand other cultures using concepts such as individualism and collectivism" (p. 45). The new environment requires graduates who (a) are capable of addressing the unique challenges faced by the small business from a global perspective and (b) can effectively collaborate with individuals within firms from different countries and cultures.

Despite strong demand for interculturally competent graduates, the training in universities falls short (Deardorff, 2006; Johnson, Lenartowicz \& Apud, 2006). This is especially true for graduate programs, as internationalization of higher education has been primarily focusing on undergraduate curricular and cocurricular initiatives (Ferren \&Merrill, 2013). Even though MBA programs tend to have a strong international component, the curricula typically emphasize business competitiveness on a global platform and expansion to foreign markets (Kao \& Mao, 2011). The present authors take a different tack. To empower future educators and future small business owners, the global entrepreneurial perspective developed in this project combines the two critical expectations of higher education (a) support the development of intercultural competencies; and (b) support the economic development of the community through strengthening small businesses. 


\section{Importance of an Entrepreneurship Perspective}

Entrepreneurship implies a distinctive approach to managing a business or organization at varying lifecycle stages (e.g. start-up, growth). This unique approach involves opportunity assessment, resource evaluation, innovative decision making, and willingness to assume some risk (Eisenmann, 2013). Kao and Mao (2011) cite a need for innovative (entrepreneurial) thinking in contemporary business-related curricula. There is also growing agreement across counties, governments, and universities that entrepreneurial capabilities are critical to coping with change, identifying opportunities, developing new products and innovations, creating jobs, and fueling economic growth (Audretsch, Thurik, Verhuel, \& Wenneker, 2002; Thurik, Stam, \& Audretsch, 2013). Research by Martin, McNally, and Kay (2013) addressed the increasing global need for countries to develop and grow human capital as well as undertake more research concerning both domains of entrepreneurial preparation (i.e., education and training). The course presented in the present project addresses this call for contemporary entrepreneurship education and training, along with cutting edge competitive information and concepts for global retail entrepreneurs.

Entrepreneurship has demonstrated exceptional growth as a discipline and curricular area at the university level (Duval-Couetil, Gotch, \& Yi, 2014). This trend is reflected in the number of undergraduate students enrolled in U.S. entrepreneurship courses, as well as at other academic institutions globally. Furthermore, there has been extensive growth in entrepreneurship course offerings outside of business colleges (Kuratko, 2005; Solomon, Duffy, \& Tarabishy, 2002). The entrepreneurial interests of non-business students frequently relate to categories with a high incidence of business start-up, such as independent retail firms, restaurants, and apparel design firms. Frazier and Niehm (2008) concluded that greater knowledge of the entrepreneurship-related needs, interests, and intentions of non-business school majors is essential for universities to effectively grow entrepreneurship.

Drivers of entrepreneurship education include changes in global economies, competitive job markets, and need for greater job opportunities for graduates (Rampell, 2011). However, there is a dearth of literature regarding graduate-level entrepreneurship offerings, a void addressed by the present paper. The literature (Duval-Couetil, Gotch, \& Yi, 2014) suggests that both theoretical and applied entrepreneurship curricular content is needed to adequately prepare graduate students for the contemporary global job market and to diffuse entrepreneurial activity.

In the present course, graduate student learning was fostered by retailing module content that integrated entrepreneurship and global/cultural perspectives. The combined module content was substantial, informative, theoretically grounded, and applied. As will be discussed next, distinctive aspects concerning operational challenges and opportunities for small U.S. and Indian retail businesses were conveyed through a wide variety of learning approaches across seven research-based and industry relevant modules.

\section{A Retailing Course that Encapsulates Global and Entrepreneurial Perspectives}

The long-term goal of collaborators of the present project is to affect change in U.S. retailing education in order to better prepare students to (a) enhance economic performance of retail-related small businesses operating in the United States and (b) be sensitive to the business and cultural context when seeking retailing-related opportunities in other regions of the world. To this end, cultural diversity and entrepreneurship were not only two of seven learning modules (i.e., Cultural Diversity, Retail Entrepreneurship), but also acted as overarching elements that guided course development. This included the selection of content (e.g., case studies, research articles, and industry literature) and development of instructional materials (e.g., PowerPoint presentations) and learning activities (e.g., reflective assessments, application of concepts) in the remaining five modules: Assortment Planning and Allocation, Triple Bottom Line Retail Strategies, Experiential Marketing, Promotional Strategies, and Omni-Channel Retailing.

For instance, in a learning activity where students applied module concepts, they compared how small businesses in the United States and India employed entrepreneurial practices, such as reducing risk and leveraging resources (Morris \& Kuratko, 2013), through the use of experiential marketing practices (i.e., 
pop-up shops; small temporary shop). The student also analyzed how these varying practices reflected Hofestede's (2011) cultural dimensions such as individualism and collectivism.

\section{Course Development Process}

The course and module structure outlined herein provides an innovative pedagogical approach to faculty and student learning of retailing content. Development of the course entailed a partnership among faculty, students, and business professionals to apply leading-edge pedagogical and content knowledge that recognizes the needs of small, independent retailers and takes into account cultural perspectives of the United States and India.

Specifically, a team of 10 U.S. faculty and six Indian faculty members co-developed and co-taught a graduate level course. Seven faculty members from one U.S. university, two from another U.S. university, and one from a third university constituted the U.S. contingent. The seven U.S. members invited faculty members at the other U.S. institutions based on previous professional relationships. There were six Indian faculty collaborators and one administrator, who were selected by an upper administrator of the Indian institution. The U.S. team selected the Indian partner based on the preeminent status of the institute.

The project began with four monthly "getting to know you" videoconference meetings among all collaborators from three U.S. universities and six campuses of the Indian institute. These meetings via Adobe Connect helped collaborators to become familiar with each other's backgrounds, educational practices, priorities and goals, and with the needs of small retail entrepreneurs. These meetings also provided extensive opportunity for U.S. and Indian collaborators to enhance their knowledge concerning retailing, cultural differences, entrepreneurship education, and experiential and service learning.

Sub-teams were then formed, based on collaborator expertise, to develop the seven aforementioned learning modules for a graduate course. Each sub-team included at least two U.S. collaborators and one Indian collaborator. When developing their learning modules, each sub-team used the same module outline format and PowerPoint template to create a consistent brand image across the various modules. Monthly meetings of all collaborators ensured progress.

The development of learning modules took place over 10 months using Skype, Zoom, and email. Once completed, each learning module was reviewed by advisory panel members (i.e., U.S. and Indian industry professionals and academics), by U.S. graduate students, and by members of other sub-teams. Revisions to the learning modules were made and uploaded to a learning management system for student access one month before the class sessions began. This project was piloted in the United States in fall 2017 and will be replicated in India in spring 2018.

\section{Integrating the Revised Bloom's Taxonomy and Kolb's Learning Cycle}

The project collaborators agreed, it was essential to help students become critical and creative thinkers. In an effort to foster higher levels of student thinking, the cognitive skills from the Revised Bloom's Taxonomy (RBT) were considered throughout the development of the learning modules, activities, and a service-learning project, as well as development of a pretest and posttest to assess student learning. Bloom's Taxonomy was originally developed in 1956 by an educational psychologist, Benjamin Bloom, in an effort to categorize cognitive skills and learning behavior. In 2001, the original Taxonomy was revised by one of Bloom's former students, Lorin Anderson and one of Bloom's former collaborators, David Krathwohl (Wilson, 2016). The RBT includes the following six cognitive skill levels: remembering, understanding, applying, analyzing, evaluating, and creating. Recall skills (remembering) reflected the lowest level of cognitive skills and creating represented the highest level (Krathwol, 2002).

In support of the RBT, the seven modules (See Appendix A) incorporated experiential learning activities and concluded with a capstone service-learning project (See Appendix B) with a small retail business client. These activities and capstone project incorporated Kolb's (1984) four-stage learning cycle, which consists of experiencing, reflecting, thinking/conceptualizing, and acting. This capstone project aligns with an assignment outlined by Niehm, Fiore, Hurst, Lee, \& Sadachar (2015). In the 
project, student teams conducted an in-depth needs assessment with a client (i.e. small retail business owner) and market research for the client to develop a toolkit of competitive strategies tailored to the business. This project allowed graduate students to apply knowledge and theory while learning retail entrepreneurship through a real-world, hands-on experience with a small business owner. They provided informed, strategic recommendations to the business owner and assessed the applicability of these recommendations to hypothetical small businesses in an Indian context. Morris et al. (2013) suggested that experiential learning, woven together with relevant course content, can indeed provide the most impact on student learning of entrepreneurship concepts.

\section{Course Structure}

A hybrid course format was used. It entailed sub-teams of U.S. and Indian faculty members leading 2hour synchronous, interactive classroom sessions for on-campus and distance students along with presession learning materials and post-session activities available online. Whereas the course ran the full semester, the classroom sessions met during two weeks in September, while pairs of the Indian collaborators were visiting scholars distributed among the three U.S. universities. Each of the seven sessions covered one learning module. Three modules were offered in the first week (Wednesday through Friday) and the remaining four modules were offered in the second week (Monday through Thursday). As part of a service-learning project, students developed interview questions for small retail business owners during the weekend adjoining the class sessions, and they participated in a roundtable event with Main Street business owners and community leaders during the second weekend to launch the capstone project. Students completed online learning activities in October and November. Students also interviewed their small business owner client in October for the service-learning project, due at the end of the semester.

As noted, student learning was based on small in-class and post-class, module-specific activities and the service-learning group project with teams of three or four students. As an example of the small activities, for the cultural diversity module, each student was asked to apply Hofestede's (2011) cultural dimensions when formulating solutions to business issues in small retail settings in India.

\section{STUDENT LEARNING ASSESSMENT}

\section{Pretest and Posttest Assessment of Student Learning}

All 10 students who enrolled in the course completed pretest and posttest surveys, which provided insight into their satisfaction with the course design and into their personal level of learning. Only eight students gave permission to have their responses included in the analyses for research purposes. All eight participants were female and between 23 to 30 years of age $(M=27.75)$. Three students $(38 \%)$ were pursuing an MS degree, and five were doctoral students. Two students $(25 \%)$ were from the U.S., and the international students (75\%) represented a variety of countries, including India (2), China (1), Iran (1), South Korea (1), and Taiwan (1). All students, but one, had previously taken marketing/merchandising undergraduate and/or graduate courses and, therefore, they had some retail background. In addition, $75 \%$ of students had various retail industry experiences, ranging from six months to seven years $(M=2.75$ years), and they worked as a product developer, merchandiser, market analyst, or sales associate for small and large companies in the United States and abroad.

Both quantitative and qualitative student assessment and student feedback were collected at various times throughout the semester. At the beginning of the semester, students completed an online pretest survey to capture their initial level of learning reflected by 84 -items (12 items for each of the seven learning modules) built on the six levels of thinking in the Revised Bloom's Taxonomy. At the end of the semester, students completed a posttest survey with the same 84-items to assess their level of educational growth related to each learning module. In addition, students provided feedback on the learning experience by answering questions about what helped them learn in the course, major takeaways, suggestions for improvements, etc.

Based on comparison of the pretest and posttest means for each of the seven modules, it was evident that the course led to educational growth for the eight students. Posttest mean scores for each of the 84- 
items increased in comparison to the pretest scores. In order to evaluate the statistical significance of these differences, within-subject paired t-tests were employed. Of the 84 items on both the pretest and posttests, 70 items encapsulated the higher levels of thinking in the Taxonomy (understanding, applying, analyzing, evaluating, and creating). Results revealed statistically significant differences for $58(83 \%)$ of these 70 items $(p<.05)$, indicating growth and enhanced higher-level learning for the students in the class. Based on these results, it appears that grounding the learning objectives in the RBT helped students apply, analyze, evaluate, and create content through in-class discussion, out-of-class activities, and a capstone service-learning project. Because running multiple $t$-tests and a small sample size lead to an increase in Type I error and a decrease in statistical power (de Winter, 2013), testing hypotheses regarding significant differences in specific cognitive skills in specific modules was not performed.

\section{Student Feedback and Lessons Learned}

Students agreed that they learned a great deal $(\mathrm{M}=3.88$; on a five-point Likert scale, with $5=$ strongly agree) as a result of taking the course, because of its "very diverse" content (Participant 6). Half of the students believed the instructional materials developed for the seven modules were the most helpful elements for advancing their learning, as supported by the following student comments: "Cases and articles helped me understanding the key concepts of each module." (Participant 6); "Discussion in the class and small assignments [were the most helpful for my learning in the course]. The discussion lets me organize my thoughts and gives [me a] chance to know other people's idea[s]. After the class, the small assignments helped me to understand the course since I had to go back to the article." (Participant 3).

Additionally, the variety of instructional materials (e.g., PowerPoint lectures, scholarly articles, industry-based cases) in each module appeared to facilitate the learning process. For instance, Participant 2 stated, "[t]he breadth of materials available was really helpful. I liked being able to read the articles but reinforce the ideas from referencing the PowerPoints, it made the ideas really stick."

Another successful aspect of the course was the opportunity to learn from a large and diverse group of faculty members who had expertise in the module topics. For example, Participant 2 enjoyed "[a]ll the different insights of different faculty and students; the diversity of perspectives and ideas." All but one participant believed that having visiting faculty from India teaching alongside the U.S. counterparts was very helpful to better understand the Indian culture. The diverse instructional team allowed for "comparing different content and opinions from Indian and American professors" (Participant 7).

Further, the students were able to comprehend how cultural differences played into retail practices and strategies in the two markets. Participant 8 commented, "[t]he understanding of two different countries with contrasting culture[s] guided [my] understanding with respect to retail and merchandising." Students were also able to realize specificities of small business operations in the two different countries and cultures, as addressed in the following statement regarding major takeaways related to cultural components learned in the class: "Cultural differences and business strategy differences between U.S. and India small business." (Participant 8).

Finally, the most impactful component of the course in terms of student learning was the servicelearning opportunity to apply the concepts from the classroom to the real world, when working with the small business. The students agreed that the project was their favorite part of the course. Participant 4 noted, "Doing [a] practical project let me apply my actual knowledge for a small business in the U.S. context. It was a good experience." All students agreed that "hands on experience with local retailers" (Participant 7) - developing marketing strategies for a specific business - was the major take-away from the entire learning experience. Participant 1 explained, "I liked working with the local businesses, because that included applying what we learned to real word business situations." Students commented that learning about companies' needs, challenges, and limitations to sustain and/or grow their operations and using this information to develop strategies for these small businesses was a "challenging but very fulfilling" experience (Participant 2). Another student agreed, "I like the practical final project report involving analysis and recommendation of business operations for a retailer that needed to grow" (Participant 8). 
When discussing recommendations for course improvements, all but one participant suggested "reduction in workload" (Participant 2). Perhaps because of the large number of faculty members involved in the development and delivery of the course, as well as a significant number of in-depth modules (seven), the course was quite complex, with a variety of activities and assessments. In general, students agreed that the "overwhelming amount of assignments made it very hard to enjoy and grasp the context of the course" (Participant 1). Participant 7 suggested, "Maybe less assignments will be good for students to better digest the course and ideas." Whereas the many professors from different universities and campuses created "a unique experience" for learning (Participant 7), it might have been overwhelming for some students to keep up; "working with numbers of faculties was complicated, everyone has different criteria" (Participant 4).

\section{IMPLICATIONS AND FUTURE OFFERINGS}

Based upon faculty experience and student feedback, the following adjustments will be made to the course for future delivery to enhance student learning:

- Explain the hybrid nature of the course and expectations in greater detail

- Have consistent formatting and expectations for assignments across modules

- Allow more time and opportunities for students to participate in class discussions

- Use smaller decks of slides in class with lengthier decks of 'supplementary' slides for reviewing before and after the class session

Additionally, students and faculty alike felt that the following were positive aspects of the course and should be kept and modified, as needed:

- The 2-week class structure allowed students to connect the module content day-to-day

- Having some assignments due before the class sessions enhanced understanding of the readings and class discussions

- Using case studies in some modules enhanced application of module concepts.

Following the course offering in India in 2018, collaborators will develop companion open source educational materials for faculty and students. A separate version of the materials for business operators will be created. The open source educational materials for faculty and students will closely align with the content of the aforementioned learning modules, but will include examples of student work from the graduate courses and service-learning case examples, with permission of the students or businesses involved. Input from advisory panel members will also shape the open source materials. The open source materials will be promoted through ads sent to listservs for relevant professional organizations and small business assistance providers. In sum, the open source educational materials, containing the course content, activities, and assignments, will be disseminated to increase the material's impact through the use by other U.S. programs that teach retailing.

\section{CONCLUSION}

The approach, integrating global and entrepreneurial perspectives presented in this paper, not only answers the call for changes in education to increase understanding of the impact of globalization on businesses (Kao \& Mao, 2011), but also aids students in better comprehension of business operations in a cultural context, as urged by Godiwalla (2016). Moreover, the approach prepares future professionals to take advantage of opportunities found in the rapidly changing retail environment. The approach provides a unique contribution; it focuses on entrepreneurial small business development rather than international expansion by major corporations. Another unique aspect is the focus on MS and Ph.D. student education, which will seed the next generation of college professors with a new perspective to disseminate to undergraduate students. The approach was implemented in a course focused on the U.S. and Indian small business contexts. However, it is a flexible structure that can be applied to development of courses addressing retail small businesses of any country and can be expanded to include other aspects of 
retailing, such as human resource management. Quantitative and qualitative data support the positive effect of the course on student learning. However, the small sample size limited the ability to statistically test hypotheses related to the course's effect on enhancement of cognitive skills. An upcoming course to be offered in India with 70 students will provide the collaborators the opportunity to statistically test the course's effect.

\section{ACKNOWLEDGEMENTS}

This project was funded in part by a grant from the United States India Educational Foundation, made possible by the US Department of State. The opinions, findings and conclusions stated herein are those of the authors and do not necessarily reflect those of the United States-India Educational Foundation and Department of State. We would like to acknowledge the contributions of other U.S. team members (Cosette Armstrong, Eulanda Sanders, Jane Swinney), and the National Institute of Fashion Technology collaboration director (Sibichan Mathew) and faculty collaborators (Siewspah Buhroy, Amandeep Singh Grover, Vikas Kumar, Krishnakumar Mallaiyan, G.H.S. Prasad, Sushil Raturi).

\section{REFERENCES}

Audretsch, D.B., Thurik, R., Verhuel, I., \& Wennekers, S. (2002). Entrepreneurship: Determinants and policy in a European-US comparison. Boston, MA: Kluwer Academic Publishers.

ANI. (2017, February). Forever 21 expands national footprint with its 15th store in India. ETRetail.com. Retrieved from_https://retail.economictimes.indiatimes.com/news/apparelfashion/apparel/forever-21-expands-national-footprint-with-its-15th-store-in-india/57390701

Alexander, N. \& Doherty, A.M. (2009). International retailing $\left(1^{\text {st }}\right.$ Ed.). Oxford, UK: Oxford University Press.

Arora, R. (2017). FDI in multi brand retail in India. Journal of Retail Marketing \& Distribution Management, 1(1), 7-12. Retrieved from http://management.nrjp.co.in/index.php/JRMDM/article/view/21

Deardorff, D.K. (2006). Identification and assessment of intercultural competence as a student outcome of internationalization. Journal of Studies in International Education, 10(3), 241-266.

De Winter, J.C.F. (2013). Using the student's t-test with extremely small sample sizes. Practical Assessment, Research \& Evaluation, 18(10). Available online: http://pareonline.net/getvn.asp? $\mathrm{v}=18 \& \mathrm{n}=10$

Dholakia, N., Dholakia, R.R., \& Chattopadhyay, A. (2012). India's emerging retail systems: Coexistence of tradition and modernity. Journal of Macromarketing, 32(3), 252-265. doi: $10.1177 / 0276146712438900$

Dixit, R. \& Singh, S. (2017). Growth of retail market in India. Journal of Retail Marketing \& Distribution Management, 1(1), 13-17. Retrieved from

http://management.nrjp.co.in/index.php/JRMDM/article/view/22

Duval-Couetil, N., Gotch, C.M., \& Yi, S. (2014). The characteristics and motivations of contemporary entrepreneurship students. Journal of Education for Business, 89(8), 441-449. doi: $10.1080 / 08832323.2014 .933156$

Eisenmann, T.R. (2013). What is entrepreneurship. Harvard Business Review. Retrieved from https://hbr.org/2013/01/what-is-entrepreneurship

Elkington, J. (1994). Towards the sustainable corporation: Win-Win-Win business strategies for sustainable development. California Management Review, 36(2), 90-100. doi: 10.2307/41165746

Fareed, Z. (2016) Populism on the march: Why the west is in trouble. Foreign Affairs, 95(6), 9-15. Retrieved from http://heinonline.org/HOL/LandingPage?handle=hein.journals/fora95\&div=119\&id=\&page= 
Farrell, D. \& Beinhocker, E. (2007, May 19). Next big spenders: India's middle class. Newsweek International. Retrieved from https://www.mckinsey.com/mgi/overview/in-the-news/next-bigspenders-indian-middle-class

Ferren, A.S. \& Merrill, M.C. (2013). The role of institutional research in supporting internationalization of higher education. Journal of Higher Education Theory and Practice, 13(2), 45-56.

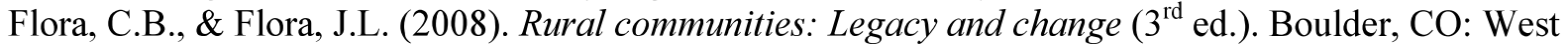
View Press.

Frazier, B., \& Niehm, L.S. (2008). An assessment of the entrepreneurial intentions of college students majoring in Family and Consumer Sciences. Journal of Family and Consumer Sciences, 100(2), 17-24.

Global retail development index. (2017). AT Kearney. Retrieved from https://www.atkearney.com/globalretail-development-index/article?/a/the-age-of-focus-2017-full-study

Godiwalla, Y.H. (2016). International business cases: A framework for classroom discussion. Journal of Higher Education Theory and Practice, 6(3), 11-16. Retrieved from https://search.proquest.com/openview/e00275280bf47a66a7230bacd4938230/1?pqorigsite $=$ gscholar $\& \mathrm{cbl}=766331$

Guerin, S.H. (2009). Internationalizing the curriculum: Improving learning through international education: Preparing students for success in a global society. Community College Journal of Research and Practice, 33, 611-614. doi: 10.1080/10668920902928945

Hofstede, G. (2011). Dimensionalizing cultures: The Hofstede Model in context. Online Readings in Psychology and Culture, 2(1). doi: 10.9707/2307-0919.1014

India Brand Equity Foundation. (2017). Retail industry in India. Government of India: Ministry of Commerce \& Industry. Retrieved from https://www.ibef.org/industry/retail-india.aspx

Johnson, J.P., Lenartowicz, T., \& Apud, S. (2006). Cross-cultural competence in international business: Toward a definition and a model. Journal of International Business Studies, 37, 525-543. doi: 10.1057/palgrave.jibs.8400205

Joshi, A., Dheri, V., Goel, S., \& Pillai, S. (2014, June). Expanding horizons of global retailers in India. Retrieved from http://www.rai.net.in/Replenish/88420123_cbre.pdf

Kao, D. \& Mao, T. (2011). A framework for aligning business education with dynamic changes in global competition. Journal of Higher Education Theory and Practice, 11(1), 9-20.

Kolb, D. (1984). Experiential learning: Experience as the source of learning and development. Englewood Cliffs, NJ: Prentice-Hall.

Krathwohl, D.R. (2002). A revision of Bloom's taxonomy: An overview. Theory into Practice, 41(4), 212-18. doi: 10.1207/s15430421tip4104_2

Kuratko, D.F. (2005). The emergence of entrepreneurship education: Development, trends, and challenges. Entrepreneurship Theory and Practice, 29(5), 577-598. doi: 10.1111/j.15406520.2005.00099.x

Martin, B.C., McNally, J.J. \& Kay, M.J. (2013). Examining the formation of human capital in entrepreneurship: A meta-analysis of entrepreneurship education outcomes. Journal of Business Venturing, 28(2), 211-224.

Morris, M.H., Kuratko, D.F., \& Cornwall, J.R. (2013). Entrepreneurship programs and the modern university. Northampton, MA, USA: Edward Elgar Publishing.

National Retail Federation. (2014). NRF forecasts $4.1 \%$ increase in retail sales for 2014 [Press release]. Retrieved from https://nrf.com/media/press-releases/nrf-forecasts-41-increase-retail-sales-2014.

National Retail Federation. (2015, July). National Retail Federation revises annual economic forecast. Retrieved from https://nrf.com/media/press-releases/national-retail-federation-revises-annualeconomic-forecast

Niehm, L.S., Fiore, A.M., Hurst, J., Lee, Y., \& Sadachar, A. (2015). Bridging the gap between entrepreneurship education and small rural businesses: An experiential service-learning approach. Journal of Business and Entrepreneurship, 26(3), 129-161. Retrieved from https://search.proquest.com/docview/1679958982?accountid=10906 
Pine, B.J. II \& Gilmore, J.H. (1999). The experience economy. Boston, MA: Harvard Business School Press.

PTI Consultancy. (2017, September). Indian middle class offers opportunities for US exports: American diplomat. The Economic Times. Retrieved from

http://economictimes.indiatimes.com/news/economy/foreign-trade/indian-middle-class-offersmajor-opportunities-for-us-exports-american-diplomat/articleshow $/ 60490523 . \mathrm{cms}$

Rampell, C. (2011, July). The help-wanted sign comes with a frustration astrick. The New York Times. Retrieved from http://www.teamsters952.org/Help-Wanted_Ads_Exclude_the_LongTerm Jobless - NYTimes.com.pdf

Rathi, A. (2014, February). India's urban work boom is leaving women behind. The Conversation. Retrieved from https://theconversation.com/indias-urban-work-boom-is-leaving-women-behind22668? ga=1.182207207.1544767521.1408925338.

Singh, K. (2014). Retail sector in India: Present scenario, emerging opportunities and challenges. Journal of Business and Management, 16(1), 72-81. Retrieved from http://www.iosrjournals.org/iosrjbm/papers/Vol16-issue4/Version-1/J016417281.pdf

Singhi, A., Mall, A., \& Puri, N. (2016, January). CII national retail summit: 2016: Retail transformation: Changing your performance trajectory. The Boston Consulting Group. Retrieved from https://media-publications.bcg.com/india/Retail-Transformation.pdf

Solomon, G.T., Duffy, S. \& Tarabishy, A. (2002). The state of entrepreneurship education in the United States: A nationwide survey and analysis. International Journal of Entrepreneurship Education, $1(1), 65-86$.

Sternquist, B. (2007). International retailing ( $2^{\text {nd }}$ Ed.). New York, NY: Fairchild Fashion Group

Suominen, K. (2017 April). Globalization 4.0: How the internet and e-commerce are hacking protectionism [blog post]. Originally published in Zocalo. Retrieved from https://katisuominen.wordpress.com/

Thurik, A.R., Stam, E., \& Audretsch, D.B. (2013). The rise of the entrepreneurial economy and the future of dynamic capitalism. Technovation, 33(8-9), 302-310. doi: 10.1016/j.technovation.2013.07.003

Whalen, P.S. \& Akaka, M.A. (2016). A dynamic market conceptualization for entrepreneurial marketing: The co-creation of opportunities. Journal of Strategic Marketing, 24(1), 61-75.

Wilson, L.O. (2016). Anderson and Krathwohl: Bloom's Taxonomy Revised: Understanding the new version of Bloom's Taxonomy. The Second Principle: The work of Leslie Owen Wilson, Ed. D. Retrieved from: https://thesecondprinciple.com/teaching-essentials/beyond-bloom-cognitivetaxonomy-revised/

Wilkinson, T., \& Brouthers, L.E. (2006). Trade promotion and SME export performance. International Business Review, 15, 233-252.

Zahra, S.A., Sapienza, H.J., \& Davidsson, P. (2006). Entrepreneurship and dynamic capabilities: A review, model and research agenda. Journal of Management Studies, 43(4), 917-955. 


\section{APPENDIX A}

\section{The Seven Course Modules}

Descriptions and learning outcomes for each module, shared with students, are presented. Students also received information on delivery methods, learning resources, and module content, but space limitations prohibited their inclusion in this paper.

\section{Cultural Diversity}

Module description: In today's global economy, understanding differences in cultures is important to professional success and personal life. The United States of America, representing a Western individualistic society, is the oldest democracy, whereas India, representing an Eastern collectivistic society, is the largest democracy. The cultural diversity module will allow you to explore similarities and differences between these diverse democracies through the lens of Hofstede's cultural dimensions. You will compare gender roles, corporate culture, and the apparel/fashion retail industries of these countries. This module will also cover etiquette, mannerisms, slang, communication styles, educational systems, and other cultural nuances in an interesting and engaging manner. As a part of this module, you will read three relevant assigned articles covering the topical areas and work on scenario-based class activities. A secondary reading list will be provided to allow for greater understanding of Indian and United States culture. At the end of this module, you will appreciate the similarities and differences between these two cultures, which will prepare you to be successful retail entrepreneur in the global fashion industry.

Learning outcomes: a) Explore similarities and differences between United States and India through the lens of Hofstede's cultural dimensions, b) Apply Hofstede's cultural framework in the context of the fashion-related retail industry, with a focus on small entrepreneurial businesses, c) Compare gender roles, business culture, and the types of business structures (small and large) in the fashion-related retail industries of the United States and India, d) Recognize etiquette, mannerisms, slang, communication styles, educational systems, and other cultural nuances in the United States and India, e) Formulate strategies to resolve issues in small retail business settings, and f) Employ Hofstede's framework to study different cultures within India.

\section{Retail Entrepreneurship in Small Non-Urban Markets}

Module description: This module will provide students with an understanding of the characteristics, challenges, and opportunities associated with retail entrepreneurship in rural and urban areas. An overview will be provided of issues associated with entrepreneurship and small retail business operation in the United States and India. Flora and Flora's community capitals framework will be used to explore resources and opportunities in evolving rural communities through entrepreneurship. The interdependence between retailers and their communities will also be examined. Students will gain insight concerning operational and competitive strategies appropriate for small retailers in non-urban markets of the United States and India. Sources of competitive advantage for small retailers will be examined using a resource based view perspective. Students will apply knowledge gained from the module to recommend strategies and practices for small retail business scenarios.

Learning outcomes: a) Analyze contributions of small independent retailers to local community markets, b) Understand retailer and community interdependence from a community capital perspective, c) Identify formal and informal sources of small business assistance and networks, and d) Develop and apply operational and competitive strategies to enhance small business competitive advantage and sustainability in non-urban areas.

\section{Assortment Planning and Allocation}

Module description: The module will begin with a discussion of strategies for planning inventory investment and assortment planning practices by small entrepreneurial retailers vis-à-vis larger retailers in both India and the United States. Effective inventory management topics to be covered include how to: manage costs and space allocation, measure shrinkage and improve the customer shopping experience. 
Next, the module will cover model stocks and basic stocks as a means to understand the importance of planning regular inventory replenishment. Lastly, the module will touch on the importance of allocation to small firms. Allocating inventory will focus on helping the entrepreneur to formalize their inventory classifications and refine these for future business growth. Analysis of sales by classification will guide the discussion on the allocation of inventory. The goal of this module is a more thorough understanding of the need for inventory planning so that firms can maximize their return on investments.

Learning outcomes: a) Explore similarities and differences between the United States and India regarding assortment planning practices through the lens of a small, independent retailer, b) Compare and contrast assortment planning practices of small independent retailers versus large retail or specialty chains in both the United States and India, c) Gain a more thorough understanding regarding the importance of inventory planning and a balanced assortment, and d) Identify assortment planning and inventory management strategies that will maximize the small retail entrepreneur's inventory investments.

\section{Triple Bottom Line}

Module description. Triple Bottom Line (TBL) is a term coined by John Elkington (1994), which measures the economic, environmental, and social performance of a business, and it is a practical framework of sustainability. The idea behind the TBL paradigm is that a corporation's ultimate success or health can and should be measured not just by the traditional financial bottom line but also by its social/ethical and environmental performance. This framework includes long-term, systems, and lifecycle thinking. This module will start with an introduction to TBL and a discussion about the main concepts that underlie TBL, such as climate change, product/service lifecycle, living wage, and resource depletion. Then, this framework will be relevant to small and medium size entrepreneurial enterprises within two cultural systems.

Learning outcomes: a) Analyze sustainability tradeoffs for retail entrepreneurs within a systemsthinking lens, b) Identify strategies to foster social and environmental gains by small businesses, and c) Gain insight about the TBL scenario in India.

\section{Promotional Strategies}

Module description: Promotion, one of the 4P's of the marketing mix, enables a brand to build brand loyalty and thus play an important role in the overall marketing strategy of small retail entrepreneurs in today's global marketplace. The module on "Promotional Strategy" will include discussions on the promotion mix (e.g., advertising, sales promotions, direct marketing), principles of promotional strategies, management, and media planning in today's dynamic retail environment in order to address the increasing diversity in the use of various platforms, both traditional (e.g. visual merchandising, direct mailers, etc.) as well as non-traditional (e.g. social media, push notification on mobile devices such as SMS, etc.). The module will also include case studies and discuss various real-world situations to highlight the use and importance of the above mentioned key concepts to retail entrepreneurs. Students will gain hands-on learning experience of using the frameworks and concepts discussed in this module in a scenario-based case study of a small business that concludes the module.

Learning outcomes: a) Demonstrate and understand the definition and concepts of promotional strategy, b) Compare and contrast various elements of promotional strategy including marketing mix, traditional vs. non-traditional media and traditional marketing communication process vs. IMC, and c) Explain and evaluate promotional strategies and tools for marketing small retail-related businesses.

\section{Experiential Marketing}

Module description: The module provides students with an understanding of experiential marketing concepts. The module focuses on customer-centric activities that small retail entrepreneurs may adopt to create long-term relationships with customers. This module will provide students with insight into a strategic framework for experiential marketing that is applied to contemporary fashion/lifestyle-related 
retail business scenarios, with a specific focus on applications for small businesses, including femaleowned and rural businesses.

Learning outcomes: a) Understand the foundations of experiential marketing, b) Understand the elements of the strategic framework for experiential marketing, c) Evaluate effectiveness of strategic framework elements to enhance rural small businesses, d) Apply the experiential marketing framework to develop a strategy set that leads to competitive advantage for small retail entrepreneurs and a memorable, value-added experience for customers.

\section{Omni-Channel Retailing}

Module description: With the continuous development of technology, retailers of all sizes have been altering and engineering new ways for customers to shop and to connect with companies. The core of this module is to enhance your understanding of the strategic integration of brick-and-mortar stores, electronic retailing, direct marketing methods, and other retail channels for small retail businesses. Upon completion of this module, you will be able to identify the characteristics of multi-, cross-, and omni- channel retailing; evaluate current omni-business practices in the retail industry; and summarize the history, privacy, security, and net neutrality of omni-channel retailing. Current trends and practices influencing the development and execution of omni-channel retailing will be discussed from a consumer behavior perspective during the session. The module will conclude with a mini assignment and presentation of the emerging trends for small apparel omni-channel companies.

Learning outcomes: a) Demonstrate and understand the definition and concepts of channel strategy including multi-channel, cross-channel and omni-channel strategy, b) Compare and contrast various channels strategies, c) Explain and evaluate omni-channel strategies and their impact on small businesses, and d) Evaluate the impact of various existing and new technologies as well as key retail areas (e.g. product development, supply chain) on omni-channel strategy.

\section{U.S./India Small Non-Urban Retail Business Assessment}

\section{Final Assignment Description and Objectives}

The project focused on identifying rural community characteristics and competitive strategies to strengthen local fashion and lifestyle retail businesses in the United States and India. Project activities provided students with understanding of trends and issues affecting independent business owners in small rural communities of the United States and India. Students developed viable competitive strategies for small rural retailers and analyzed the appropriateness of these strategies for small rural retailers in the Indian market context. All students were expected to participate in the Rural Community Site Visit and Roundtable Session. Distance students connected to key components of the session via distance technology. 


\section{APPENDIX B}

\section{Capstone Assignment: A Service-Learning Project}

The capstone team assignment consisted of four sequential parts.

\section{Part $1 a$}

Students developed a community leader interview instrument to gather information about social and economic aspects of the community. The instrument facilitated collection of the following data: demographics, composition of community residents, economic stability, retail sector performance, shopping behavior, and unique cultural aspects of the community. Information was gathered through a community roundtable.

\section{Part $1 b$}

Students developed an instrument to gather information about the business owner's background, target customer, goals for the business, and current use of business strategies as they relate to the six course modules, excluding the cultural diversity module.

\section{Part 2}

A SWOT analysis was conducted, major competitors were evaluated, and the market situation and potential were collated using secondary sources.

\section{Part 3}

A "strategy toolkit" was created to enhance the client's business. Students developed eight strategies to improve the business; the strategies reflected content from at least four of the six modules. Steps, timelines, and resources needed to execute each strategy were part of the toolkit. Marketing materials with visual detail were created for at least two of the selected strategies. The U.S. collaborators were responsible for grading Parts one through three.

\section{Part 4}

Students examined the applicability of the strategic toolkit to small Indian retail business in a rural community context. Students compared and contrasted similarities and differences in small rural retailers needs and strategic options across the United States and Indian markets and identified unique requirements in each market. The Indian collaborators graded Part four. 